\title{
MINIREVIEW
}

\section{Virus Like Particles as Immunogens and Universal Nanocarriers}

\author{
ANTONINA NASKALSKA ${ }^{1}$ and KRZYSZTOF PYRĆ ${ }^{1,2 *}$ \\ ${ }^{1}$ Malopolska Centre of Biotechnology, Jagiellonian University, Kraków, Poland \\ ${ }^{2}$ Microbiology Department, Faculty of Biochemistry Biophysics and Biotechnology, \\ Jagiellonian University, Kraków, Poland \\ Submitted and accepted 5 February 2015
}

\begin{abstract}
Over the last two decades virus-like particles (VLPs) have become an important tool in biomedical research and medicine. VLPs are multiprotein structures that resemble viable virus particles in conformation but lack the viral genome. Consequently, they are non-infectious and non-replicative, but retain the ability to penetrate cells, making them useful for a vast spectrum of applications. Above all, VLPs mimicking genuine viruses in antigenic structure provide a safe alternative to attenuated and inactivated viruses in vaccine development. Moreover, due to their transducing proprieties, VLPs may efficiently deliver foreign nucleic acids, proteins, or conjugated compounds to the organism, or even to specific cell types. Additionally, VLPs are versatile nanovectors due to their flexibility in terms of composition and expression systems. In this review, different approaches for of virus-like particle synthesis and manipulation, as well as their potential applications, will be discussed.
\end{abstract}

Ke y w o r d s: delivery platform, vaccines, virus like particles (VLPs)

\section{Virus-like particles}

Virus-like particles (VLPs) are empty multiprotein structures closely resembling natural virions. Due to the absence of the genetic material, VLPs are replication- and infection-incompetent. They are formed spontaneously by the self-assembly of viral proteins during infection or by in vitro protein expression, usually in a eukaryotic system. Therefore, VLPs can be classified depending on the original virus taxonomy (e.g., adenovirus, coronavirus, etc.) or depending on the synthesis method (e.g., animal, yeast, plant, or cellfree expression). Another classification of VLPs relies on their architecture and distinguishes enveloped and non-enveloped VLPs, as well as native or chimeric VLPs. Non-enveloped VLPs are typically composed of one or more viral structural proteins, whereas enveloped VLPs consist of the host cell membrane with viral proteins displayed on the outer surface (Fig. 1) (Kushnir et al., 2012). Non-enveloped VLPs are easier to produce and purify, but enveloped VLPs are more flexible, as antigens from different pathogens can be integrated. However, they may also contain host's proteins, which may affect downstream applications (Buonaguro et al., 2011).

\section{Expression systems}

Animal cells are the most convenient expression system for virus-like particles because of their ability to carry out the complex post-translational modifications that are required for proper protein folding. Genes encoding viral proteins of interest are introduced into the host cell by plasmid transfection or viral transduction (using retroviruses, lentiviruses, adenoviruses, or adeno-associated viruses for mammalian cells, or baculoviruses for insect cells). Depending on the method used, the transgene is integrated into the genome or replicates in an episomal form. The expressed viral proteins spontaneously self-assemble within the cell, as during viral infection. Mammalian (CHO, BHK, HEK-293T, COS-11 and Vero), avian (ELL-0) and insect (Lepidoptera: Spodoptera frugiperda and Trichoplusia ni) cells have been used for VLPs production in animal expression systems (Kushnir, et al., 2012). Examples of VLPs produced in animal cells and other expression systems are provided in Table I. Despite the fact that enveloped and non-enveloped, native and chimeric VLPs are efficiently formed in mammalian cells, this expression system has some limitations, including high production costs, potential safety concerns, and

* Corresponding author: K. Pyrć, Microbiology Department, Faculty of Biochemistry Biophysics and Biotechnology, Jagiellonian University, Kraków, Poland; e-mail: k.a.pyrc@uj.edu.pl 


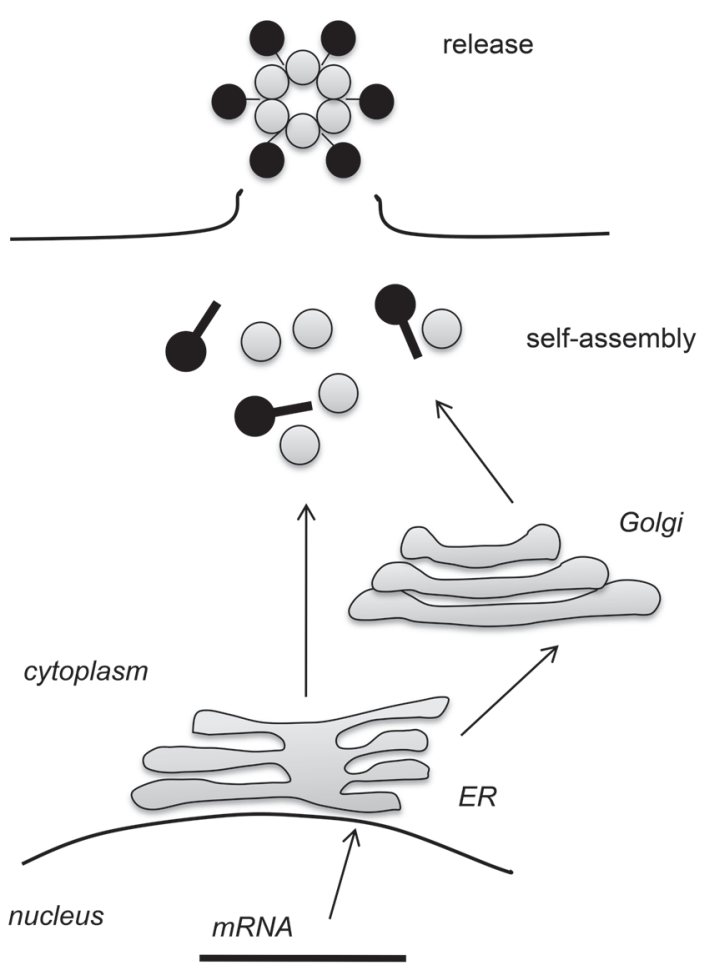

Non-enveloped VLP formation

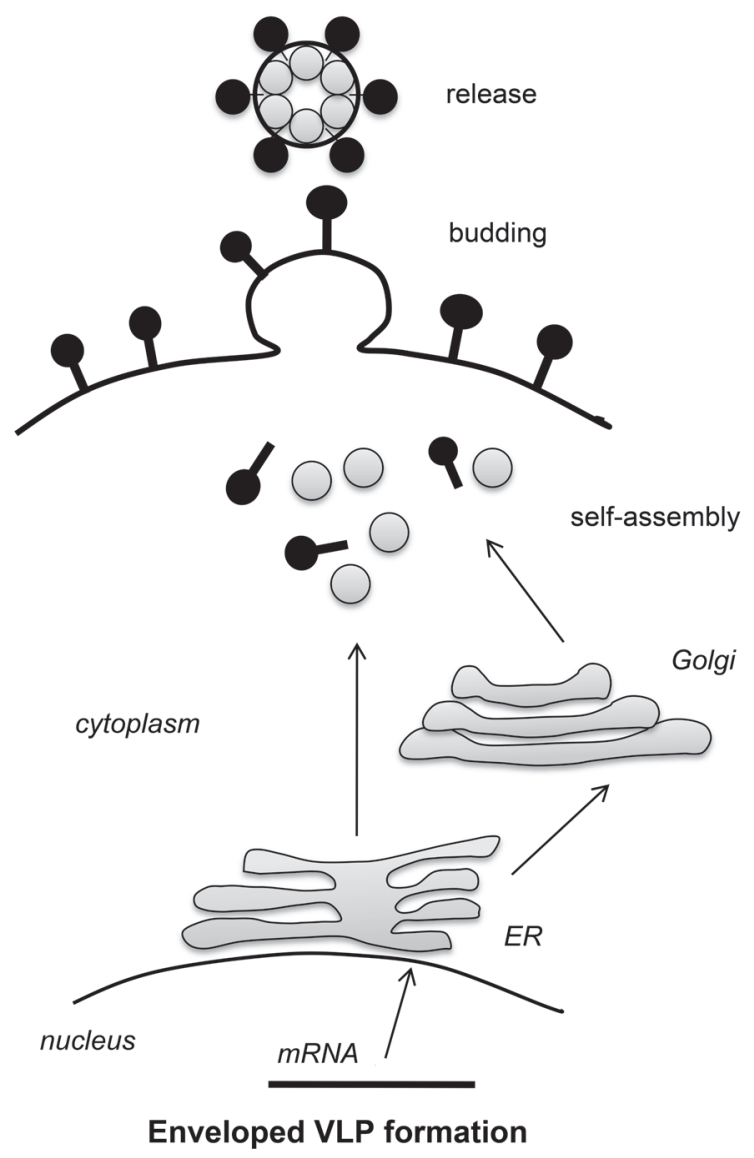

Enveloped VLP formation

Fig. 1. Schematic representation of the formation of non-enveloped and enveloped VLPs.

difficulties with scaling up production. By contrast, insect cell expression system offers significant advantages for VLPs production. Not only is this system less expensive, but it is also easier to scale up and can be used for the simultaneous expression of many proteins, facilitating the assembly of VLPs (Liu et al., 2013, Rychlowska et al., 2011). Furthermore, insect cells have the ability to post-translationally process and modify the recombinant proteins, similarly to their mammalian counterparts. Lastly, insect cells can be cultured without supplements derived from mammalian organisms, and therefore the risk of contaminating of VLPs developed for human therapy with opportunistic pathogens is minimal (Roy and Noad, 2008). Importantly, baculoviruses infect only a small group of Lepidoptera and represent no threat to humans.

Yeast cells are a well-established system for the expression of recombinant proteins. It is, however, important to remember that this system has some drawbacks that are worth considering. Yeast cells differ from mammalian cells in their post-translational modification of expressed proteins, particularly protein glycosylation pattern. For this reason, yeast is used mostly for the production of non-enveloped VLPs. However, a number of studies have demonstrated successful self-assembly of VLPs in Pichia pastoris or Sac- charomyces cerevisiae cells, and two popular vaccines licensed worldwide; against hepatitis B virus (HBV) and human papilloma virus (HPV) are based on VLPs produced in yeast. Interestingly, VLPs formation of HBV proteins has never been observed in yeast cells, but it is presumed that self-assembly takes place during the processing of the yeast biomass (Lünsdorf et al., 2011).

Plant expression systems represent another option for VLP synthesis that is cost-effective, scalable, and free of mammalian pathogens. Expression of recombinant proteins in plants can be achieved either via stable or transient transfection of the transgene into the cell. Both enveloped and non-enveloped, as well as native and chimeric, plant-produced VLPs have progressed into clinical development (Scotti and Rybicki, 2013). Interestingly, plant viral vectors used for transformation such as Tobacco mosaic virus (TMV), Alfalfa mosaic virus (A1MV), Cowpea mosaic virus (CPMV), and Papaya mosaic virus (PapMV) may incorporate recombinant proteins (even if these are not of viral origin) to form chimeric VLPs. This strategy has been used to obtain prophylactic vaccine candidates against viruses $\mathrm{HBV}$, influenza virus, respiratory syncytial virus (RSV), Norwalk virus (NV), bacteria (Staphylococcus aureus, Pseudomonas aeruginosa, Bacillus anthracis, and Yersinia pestis) and protozoa (Plasmodium falciparum) 
Table I

Different expression systems for diverse virus-like particles. Chimeric VLPs are denoted with an asterix*; the exterior protein is in the first position and the scaffold protein in the second.

\begin{tabular}{|c|c|c|c|}
\hline Expression system & VLP & $\mathrm{E} / \mathrm{NE}$ & Reference \\
\hline \multicolumn{4}{|l|}{ Mammalian } \\
\hline CHO: & HBsAg & $\mathrm{NE}$ & (Soulié et al., 1991) \\
\hline BHK: & Hantaan & $\mathrm{E}$ & (Betenbaugh et al., 1995) \\
\hline Vero: & Influenza & $\mathrm{E}$ & (Barrett et al., 2009) \\
\hline COS-1 & DENV & $\mathrm{E}$ & (Chang et al., 2003) \\
\hline \multirow[t]{3}{*}{ HEK: } & Ebola & $\mathrm{E}$ & (Yamayoshi and Kawaoka, 2007) \\
\hline & Marburg & $\mathrm{E}$ & (Kolesnikova et al., 2004) \\
\hline & Chikungunya & $\mathrm{E}$ & (Akahata et al., 2010) \\
\hline \multicolumn{4}{|l|}{ Avian } \\
\hline Fibroblasts ELL-0: & Nipah-NDV & $\mathrm{E}$ & (McGinnes et al., 2010) \\
\hline \multicolumn{4}{|l|}{ Insect } \\
\hline \multirow[t]{6}{*}{ Spodoptera frugiperda: } & Influenza & $\mathrm{E}$ & (Pushko et al., 2005) \\
\hline & RSV-Influenza M1 protein* & $\mathrm{E}$ & (Quan et al., 2011) \\
\hline & HIV & $\mathrm{NE}$ & (Gheysen et al., 1989) \\
\hline & NV & $\mathrm{NE}$ & (El-Kamary et al., 2010) \\
\hline & \begin{tabular}{|l|}
$\mathrm{RV}$ \\
\end{tabular} & $\mathrm{E}$ & (Zeng et al., 1994) \\
\hline & $\mathrm{HCV}$ & $\mathrm{E}$ & (Baumert et al., 1998) \\
\hline \multirow[t]{2}{*}{ Trichoplusia ni: } & HPV & $\mathrm{NE}$ & (Harper et al., 2004) \\
\hline & HEV & $\mathrm{NE}$ & (Li et al., 2000) \\
\hline \multicolumn{4}{|l|}{ Plant } \\
\hline \multirow[t]{3}{*}{ Nicotiana tabacum: } & $\mathrm{HBV}(\mathrm{HBcAg})$ & $\mathrm{NE}$ & (Pniewski, 2012) \\
\hline & \begin{tabular}{|l|l} 
HIV \\
\end{tabular} & $\mathrm{NE}$ & (Rosales-Mendoza et al., 2012) \\
\hline & Bacillus anthracis-CPMV ${ }^{\star}$ & $\mathrm{NE}$ & (Phelps, et al., 2007) \\
\hline \multirow[t]{3}{*}{ Nicotiana benthamina } & Influenza - TMV ${ }^{*}$ & $\mathrm{NE}$ & (Petukhova et al., 2014) \\
\hline & Rabies - A1MV* & $\mathrm{NE}$ & (Yusibov et al., 2002) \\
\hline & FMDV - TMV ${ }^{*}$ & $\mathrm{NE}$ & (Wu et al., 2003) \\
\hline Arabidopsis thaliana & HIV/HBV (HBsAg)* & $\mathrm{NE}$ & (Greco et al., 2007) \\
\hline \multicolumn{4}{|l|}{ Yeast } \\
\hline \multirow[t]{4}{*}{ Pichia pastoris } & HBV (HBsAg) & $\mathrm{NE}$ & (Lünsdorf, et al., 2011) \\
\hline & NV & $\mathrm{NE}$ & (Tomé-Amat et al., 2014) \\
\hline & $\mathrm{HCV}$ & $\mathrm{E}$ & (Acosta-Rivero et al., 2001) \\
\hline & DENV (Dengue virus) & $\mathrm{E}$ & (Tang et al., 2012) \\
\hline \multirow[t]{3}{*}{ Saccharomyces cerevisiae: } & HPV & $\mathrm{NE}$ & (Woo et al., 2008) \\
\hline & HIV & $\mathrm{NE}$ & (Sakuragi et al., 2002) \\
\hline & RV & $\mathrm{E}$ & (Rodríguez-Limas et al., 2011) \\
\hline Hensuela polymorpha: & HBV (HBsAg) & $\mathrm{NE}$ & (Seo et al., 2008) \\
\hline \multicolumn{4}{|l|}{ Bacteria } \\
\hline \multirow[t]{2}{*}{ Escherichia coli: } & HCV-PapMV ${ }^{\star}$ & $\mathrm{NE}$ & (Denis et al., 2007) \\
\hline & P. falciparum-HBcAg* & $\mathrm{NE}$ & (Sällberg et al., 2002) \\
\hline Lactobacillus casei: & HPV & $\mathrm{NE}$ & (Aires, et al., 2006) \\
\hline
\end{tabular}

E- enveloped, NE - non-enveloped.

(Table I). Cultured cells originating from Nicotiana benthamina and N. tabaccum are widely used plant cells to generate VLPs (Scotti and Rybicki, 2013).

Bacteria, the most widely used expression system for recombinant proteins are not the host cell of choice for
VLPs synthesis, due to the absence of post-translational modifications, imperfect disulfide bond formation, and problems with solubility (Zeltins, 2013). Nevertheless, bacteria are used to produce non-enveloped VLPs, often by means of a recombinant bacteriophage with 
foreign epitopes fused to surface proteins (Tissot et al., 2010). Another strategy relies on prokaryotic expression of viral protein in the form of insoluble inclusion bodies, followed by purification under denaturing conditions, refolding, and in vitro self-assembly (SánchezRodríguez et al., 2012). Even though E. coli remains the most commonly used bacterial host for VLP production, some groups have successfully produced VLPs in Lactobacillus (Aires et al., 2006) and Pseudomonas (Phelps et al., 2007) host species.

VLPs may also be formed by proteins produced in cell-free expression systems and assembled in vitro. Further modification of this approach is to incorporate expressed proteins into virosomes, which are also categorized as VLPs by some authors. Virosomes, defined as synthetic lipid or polypeptide scaffoldings decorated with viral antigens, were evaluated as vaccine candidates as early as in the 1970s (Almeida et al., 1975, Morein et al., 1979). Two examples of licensed human virosome vaccines are Epaxal and Inflexal, which are used for hepatitis A and influenza prophylaxis, respectively. The critical change in virosome production is that currently proteins of interest are expressed in a system of choice and then incorporated into a liposome or other carrier. Initially, viral antigens originated from infectious viruses, which were inactivated, dissociated, and fractionated before processing.

\section{Applications}

VLPs have a broad range of potential applications due to the diversity and multigenicity of viruses. As shown with the examples provided above, these particles may be formulated not only of proteins originating from one virus species, but also of proteins from unrelated viruses or even different pathogens, i.e., bacteria and protozoa. Chimeric VLPs are of special interest as highly specific nanovectors for the delivery of antigens or therapeutic molecules.

\section{VLPs as vaccines}

Due to their virus-like appearance and repetitive surface structure, VLPs show high immunogenicity and antigenicity. Importantly, they interact with the immune system similarly to their parental pathogens, inducing not only humoral but also cellular response, which is not common for traditional, subunit vaccines. $B$ cell activation and the production of high antibody titers have been shown to be dependent on the conformation and epitope abundance of symmetric VLPs (Buonaguro et al., 2011). Moreover, VLPs, as exogenous antigens, are efficiently taken up by professional antigen-presenting cells (APC), particularly dendritic cells (DC), which is followed by antigen processing and presentation by MHC class II molecules, leading to stimulation of CD4+ T helper cells. On the other hand, VLPs, similarly to native viruses, are also processed in the cytosol of DC as endogenous antigens and presented by MHC class I molecules to cytotoxic CD 8+ T cells (CTLs) (Grgacic and Anderson, 2006, Groothuis and Neefjes, 2005). This cross-presentation mechanism ensures comprehensive and strong immunological responses. Additionally, numerous VLP vaccines candidates are known to possess "self-adjuvant" properties, probably due to their particulate structure and small size of $(\sim 100 \mathrm{~nm})$, which favors uptake by APC (Keller et al., 2010, Manolova et al., 2008). Potentially phasing-out adjuvants in VLPs vaccine formulations is unquestionably beneficial as it would both simplify the production process and increase the safety of the vaccine.

Of the four VLP vaccines currently on the market, those for HBV and HPV are the best described (Buonaguro, et al., 2011) (Table II). The HBV VLPs contains virus surface antigen (HBsAg) and was the first VLPs vaccine to be generated (in 1980s) (Zuckerman, 1980, Zuckerman, 1985). Its successful production was reported in mammalian (Aden et al., 1979) yeast (Valenzuela et al., 1982), insect (Takehara et al., 1988), and plant (Mason et al., 1992) expression systems. Afterwards, HBV VLPs based on the core antigen (HBcAg-VLPs) were also developed. However, these are still in the preclinical stage of evaluation and are mainly used as a platform for the presentation of foreign epitopes from heterologous pathogens or tumor antigens (Kazaks et al., 2008).

For HPV prophylaxis, VLPs are formed with L1 HPV capsid protein overexpressed in S. cervisiae or T. $n i$ is used to prepare the licensed vaccine, but HPV VLP formation was demonstrated also in P.pastoris (Hanumantha Rao et al., 2011) and plant cells (Deleré et al., 2014; Scotti and Rybicki, 2013). The HPV vaccine, which showed $98 \%$ efficacy in protecting individuals from HPV16/18 infections (which are responsible for more than $70 \%$ of invasive cervical cancers) became a milestone in cancer prevention (Deleré, et al., 2014).

As for the influenza vaccine, which must be produced de novo each year, development, production, and approval times are critical. Conventional licensed influenza vaccines are prepared from embryonated chicken eggs, inoculated individually with virus strains selected for the season. Viruses are harvested from the allantoic fluid, chemically inactivated, concentrated, and purified to remove non-viral protein contaminants. The whole production process takes several months and is often hampered by the poor growth yield of some influenza strains (Reperant et al., 2014). Therefore, the VLP-based 
Table II

VLP vaccines and vaccine candidates.

\begin{tabular}{|c|c|c|c|}
\hline VLP (protein) & Vaccine & Expression system & Development status \\
\hline HBV (HBsAg) & $\begin{array}{l}\text { Hepatitis B } \\
\text { (Engerix-B, Recombivax HB, } \\
\text { GenHevacB, Euvax B, others...) }\end{array}$ & $\begin{array}{l}\text { Bacteria } \\
\text { Yeast } \\
\text { Insect } \\
\text { Plant }\end{array}$ & $\begin{array}{l}\text { On market } \\
\text { (GlaxoSmithKline, Merck, } \\
\text { Sanofi-Pasteur, LG Life Sciences) }\end{array}$ \\
\hline HPV (L1) & $\begin{array}{l}\text { Human papilloma virus } \\
\text { (Gardasil, Cervarix) }\end{array}$ & $\begin{array}{l}\text { Yeast } \\
\text { Insect }\end{array}$ & $\begin{array}{l}\text { On market } \\
\text { (Merck, GlaxoSmithKline) }\end{array}$ \\
\hline HEV (HE antigen) & Hepatitis E (Hecolin) & Bacteria & On market (Xiamen Innovax Biotech ) \\
\hline Influenza virus & Influenza virus (Flublok) & Insect & On market USA (Protein Science Corporation) \\
\hline $\begin{array}{l}\text { Influenza } \\
\text { RSV } \\
\text { Norovirus } \\
\text { HIV } \\
\text { Parvovirus B19 } \\
\text { Rabies } \\
\text { Malaria (chimeric) }\end{array}$ & Malarivax & $\begin{array}{l}\text { Plant, insect } \\
\text { Insect } \\
\text { Cell free, insect, plant } \\
\text { Yeast } \\
\text { Insect } \\
\text { Plant } \\
\text { Bacteria }\end{array}$ & Clinical studies \\
\hline
\end{tabular}

vaccines which are faster, cheaper and safer to obtain, represent an attractive alternative (Fig. 2). An influenza VLPs vaccine produced in insect cells was approved in US in 2013, but other influenza VLP candidates, produced in plant cells, bacteria, or cell-free systems, demonstrated as effective and safe and are currently in clinical trials (Chroboczek et al., 2014; Lee et al., 2014).

Other VLP vaccines that are currently in clinical trials utilize proteins from different viruses, including respiratory syncytial virus (Glenn et al., 2013), Norwalk virus (Herbst-Kralovetz et al., 2010), human parvovi- rus B19 (Chandramouli et al., 2013), and P. falciparum (chimeric VLP) (Agnandji et al., 2012). VLPs vaccine candidates for human use, that were shown to be immunogenic in animal models but are still under preclinical investigation include: human immunodeficiency virus (HIV-1), severe acute respiratory syndrome coronavirus (SARS-CoV), hepatitis C virus (HCV), RSV, rotavirus (RV), dengue (DENV), rabies (Kushnir, et al., 2012; Roldão et al., 2010), and others.

Veterinary vaccinology is a distinct, broad field, which will not be discussed in this review, but VLPs

A
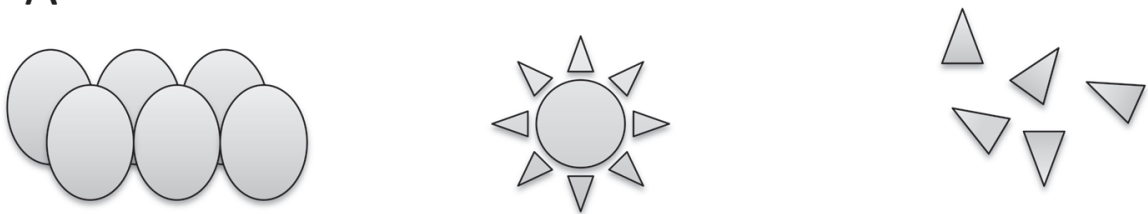

\begin{tabular}{l|ll} 
virus cultivation $\quad$ harvesting, inactivation, dissociation & antigen separation & vaccine formulation \\
\cline { 2 - 2 } egg protein contamination & detergent contamination & 6-9 months \\
\cline { 2 - 2 } &
\end{tabular}

B

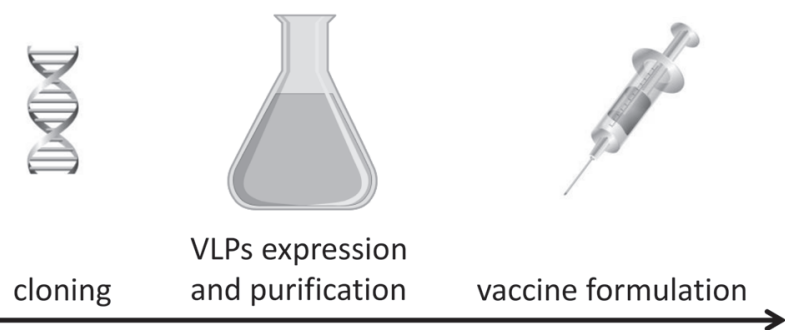

1-2 months

Fig. 2. Comparison of vaccine production using traditional virus cultures (panel A) and VLPs (panel B). 
have also been investigated as vaccine candidates for animal use (Liu et al., 2012).

As mentioned above, the plasticity of VLPs enables the formulation of chimeric vaccines loaded with heterologous antigens. This can be achieved either by coexpression of structural proteins of different viruses or by gene fusion, and results in foreign epitopes displayed on the external surface of the VLPs. The first strategy can be illustrated by the SARS-CoV VLP, where SARS spike protein is incorporated into an influenza matrix 1 protein scaffold, overcoming the problem of low yield in the production of the native SARS VLPs (Liu et al., 2011). Using the second approach the synthesis of particles that do not form native VLPs at all, becomes feasible. An anti-malaria vaccine, currently in clinical trials, is an example of a VLP displaying a non-viral antigen (S protein of P.falciparum) that is expressed as a fusion partner with HBsAg (Agnandji et al., 2012).

Alternatively, VLPs may be engineered to modulate the immune response by conjunction of adjuvants or stimulatory molecules such as Toll-like receptors (TLR) ligands and T-cell epitopes. For example, VLPs containing CpG motifs, a ligand for TLR-9, have significantly improved anti-HPV VLP humoral responses in the peripheral blood and in genital mucosal secretions in animal models (Gerber et al., 2001; Hjelm et al., 2014). Similarly, HIV VLPs equipped with cholera toxin subunit B showed increased stimulation of mucosal cellular response (Kang et al., 2003; Ludwig and Wagner, 2007). Another VLP developed to co-deliver interleukin-2 resulted in robust cytotoxic T-lymphocyte activation (Juarez et al., 2012; Oh et al., 2004). In addition to enhancing the immune response, including immunity potentiators, improves the pharmaco-kinetic profile of, VLPs reducing nonspecific binding to serum proteins.

\section{Vaccines for non-infectious diseases}

Vaccines for non-infectious diseases are an interesting application for chimeric VLPs, which are designed to induce specific antibodies directed against self-antigens and thus boost humoral immunity. These VLPs carry antigens typical for cancer (melanoma), neurode- generative diseases (Alzheimer's disease), autoimmune diseases (allergic rhinoconjunctivitis and asthma) and other disorders (Table III). Most therapeutic VLP vaccines are based on the bacteriophage $Q \beta$, which is highly expressed in E. coli, enabling the development of an economical large-scale production process. Importantly, during self-assembly, bacteriophage $\mathrm{Q} \beta$ packages host-derived RNA (the natural ligand for TLR7 and TLR8), thus activating antigen-specific IgG2a responses (Bachmann and Jennings, 2011).

\section{VLPs as delivery platforms}

The remarkable and unique advantage of VLPs as delivery vehicles is theirs specificity, which results from the receptor-mediated transduction mechanism. Similar to native viruses, most VLPs target and penetrate different cell types depending on receptors exposed at their surface. As a consequence, the diverse tropisms of parental viruses provide a range of natural targeting capabilities for VLPs, without the need for further modifications (Seow and Wood, 2009).

Decorating VLPs with foreign molecules may be achieved by various means, including genetic manipulation, non-covalent interactions, or chemical coupling of different compounds. Physical encapsulation of organic and non-organic moieties has been described as well and consists of the disassembly of purified VLPs (by osmotic shock, use of chelating agents, or varying the $\mathrm{pH}$ ) and reassembly in the presence of the desired molecule. Table IV summarizes VLPs packaging methods and examples of cargo molecules that have been successfully delivered to target cells.

Delivering drugs into target cells is particularly important for anti-proliferation chemotherapeutics, where systemic administration causes undesired sideeffects. Therefore, specific carriers, such as VLPs, are of significant interest in this field. Successful transfer of VLPs packaged with anticancer agents was described for bleomycin (BLM) and doxorubicin (DOX). Both conjugates were chemically coupled to VLPs (BLM to adenoviral VLPs and DOX to RV VLPs) and have dem-

Table III

Therapeutic VLP vaccines.

\begin{tabular}{|l|l|l|l|}
\hline \multicolumn{1}{|c|}{ VLP } & \multicolumn{1}{c|}{ Therapeutic target } & \multicolumn{1}{c|}{ Status } & \multicolumn{1}{c|}{ Ref } \\
\hline Q $\beta$-amyloid $\beta$ epitope & Alzheimer disease & Phase 2 & (Chackerian et al., 2006) \\
\hline Q $\beta$-CpG oligodeoxynucleotides & Allergic rhinoconjunctivitis and asthma & Phase 2 & (Senti et al., 2009) \\
\hline Q $\beta$-IL1 $\beta$ protein & Diabetes mellitus type 2 & Phase 2 & (Bachmann and Jennings, 2011) \\
\hline Q $\beta$-angiotensin II epitope & hypertension & Phase 2 & (Tissot et al., 2008) \\
\hline Q $\beta$-melan A peptide & Malignant melanoma & Phase 2 & (Braun et al., 2012) \\
\hline Q $\beta$-nicotine & Nicotine addiction & Phase 2 & (Maurer et al., 2005) \\
\hline HPV-TNF $\alpha$ & Arthritis & - & (Chackerian et al., 2001) \\
\hline
\end{tabular}


Table IV

VLPs as delivery platforms for foreign molecules (PyV: Polyoma virus).

\begin{tabular}{|c|c|c|c|}
\hline Cargo & VLP & Attachment & Ref. \\
\hline \multicolumn{4}{|l|}{ Proteins } \\
\hline Antibody & $\mathrm{PyV}$ & genetic fusion to VLP protein & (Gleiter and Lilie, 2003) \\
\hline GFP & RV & genetic fusion to VLP protein & (Charpilienne et al., 2001) \\
\hline MBP tag & AdV & protein adaptor & (Garcel et al., 2006) \\
\hline Enzyme & AdV & biotin-streptavidin interaction & (Fender et al., 2003) \\
\hline Cytokine (IL-2) & $\mathrm{HPV}$ & encapsulation & (Oh, et al., 2004) \\
\hline \multicolumn{4}{|l|}{ Nucleic acids } \\
\hline Plasmid DNA & $\mathrm{HPV}$ & encapsulation & (Malboeuf et al., 2007) \\
\hline RNAi & $\mathrm{PyV}$ & encapsulation & (Kimchi-Sarfaty, et al., 2003) \\
\hline \multicolumn{4}{|l|}{ Metal nanoparticles } \\
\hline Gold & AdV & encapsulation & (Fuschiotti, et al., 2006) \\
\hline Magnetic nanoparticles & HBV & encapsulation & (Pushko et al., 2013) \\
\hline \multicolumn{4}{|l|}{ Fluorophore } \\
\hline Carboxyfluorescein & HPV & chemical coupling & (Bergsdorf et al., 2003) \\
\hline Propidium iodode & $\mathrm{PyV}$ & chemical coupling & (Goldmann et al., 2000) \\
\hline Quantum dots & $\mathrm{PyV}$ & chemical coupling & (Wojta-Stremayr and Pickl, 2013) \\
\hline \multicolumn{4}{|l|}{ Drugs } \\
\hline Bleomycin & AdV & chemical coupling & (Zochowska, et al., 2009) \\
\hline Doxorubicin & $\mathrm{RV}$ & chemical coupling & (Zhao, et al., 2011) \\
\hline
\end{tabular}

onstrated improved drug bioavailability and growth inhibition of targeted cancer cells (Zhao et al., 2011; Zochowska et al., 2009).

The ability to bind nucleic acids is common for viral structural proteins and is used to pack oligonucleotides and plasmids (as well as other negatively charged substances) into VLPs (Zeltins, 2013). DNA-loaded VLPs were developed for gene therapy and aroused great hope as potential specific carriers of nucleic acids (Petry et al., 2003, Ramqvist et al., 2007). Successful expression of $\beta$-galactosidase, encoded by a plasmid delivered by a polyomavirus VP1 VLP to different tissues, demonstrated the feasibility of the VLP-mediated gene therapy concept (May et al., 2002). Up to $17 \mathrm{~kb}$ of DNA may be packaged into an SV40 polyoma VLP, as reported by Kimchi-Sarfaty (Kimchi-Sarfaty et al., 2003), but the theoretical capacity of larger VLPs is probably higher. In subsequent years, the increasing interest in use of modified small interfering RNAs as therapeutics resulted in further studies on VLPs as delivery vessels for these molecules (Seow and Wood, 2009). For example, treatment of lupus-prone mice with bacteriophage MS2 VLPs loaded with miR-146a miRNA - a recognized gene silencer - inhibited the production of auto-antibodies and inflammatory cytokines (Pan et al., 2012).

Protein delivery by VLPs has been described for heterologous antigens, antibodies, cytokines, enzymes, and reporter proteins such as green fluorescent protein (GFP) or maltose binding protein (MBP). Cargo pro- teins are usually tethered to the external surface of the VLP by genetic fusion to structural VLP protein or by exploiting natural interactions between the transported protein and structural proteins present in VLPs (antigen-antibody interactions, ligand-receptor interactions, inter-domain interactions etc.). Conjunction of Herceptin, an antibody directed against a mutated version of the tyrosine kinase receptor HER2 to the polyoma VLP is a good illustration of the potential use of VLPs in directed cancer immunotherapy (Gleiter and Lilie, 2003). Another example of a protein targeting ligand is epidermal growth factor (EGF), which was incorporated into SV40 polyoma VLPs, that selectively transduced cells overexpressing the EGF receptor (Kitai et al., 2011).

Labeling VLPs with fluorophores is another way of tethering foreign substances to these nanovectors but also a powerful research tool. Fluorescent VLPs can be traced within host cell, tissue, or organism. Viral particles can be labeled by covalent or non-covalent chemical methods or by fusion of fluorophores to proteins integrated into the viral particle. Chemical methods consist of inserting fluorescent dyes into the viral membrane. Alternatively, attachment of streptavidin-coupled fluorophores can be achieved by biotinylating target structures of interest (Wojta-Stremayr and Pickl, 2013).

The feasibility of encapsulating metal nanoparticles within the VLP cavity was shown by packaging adenovirus (AdV) VLPs with nanogold molecules (Fuschiotti et al., 2006). Recently, an interesting application 


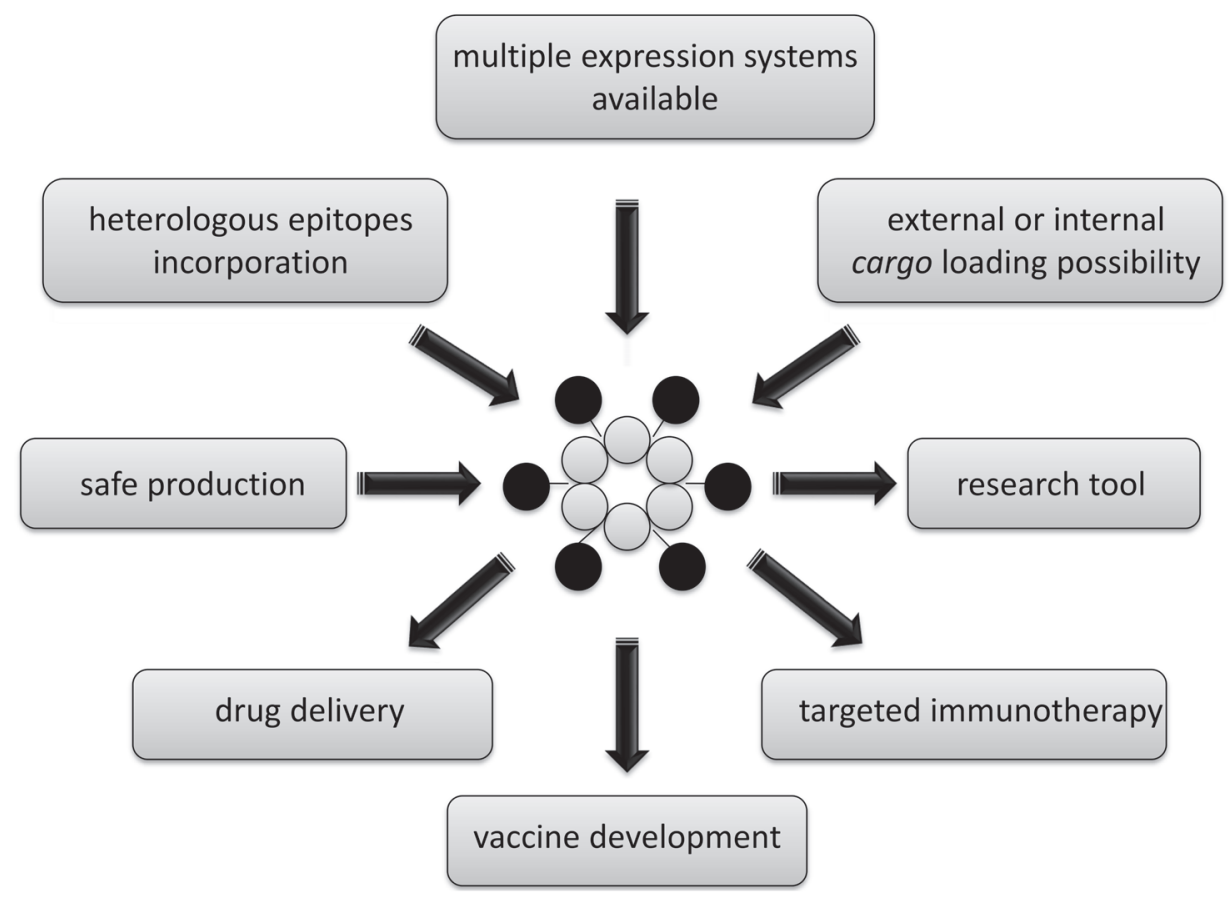

Fig. 3. Diagram showing possible VLP applications.

for another functionalized VLPs has been described providing proof of concept for the use of VLPs for diagnostic purposes. Cowpea chlorotic mottle virus (CCMV) VLP loaded with $\mathrm{Gd}^{3+}$ ions or HBcAg-VLPs loaded with $\mathrm{Fe}_{3} \mathrm{O}_{4}$ serve as paramagnetic high contrast agents for magnetic resonance imaging (Mateu, 2011, Shen et al., 2014).

Even though VLPs seem to be universal delivery platforms, they do possess several limitations, especially to their use as gene or drug carriers. The most challenging problem concerns the pre-existing immunity in most individuals for common viruses. A solution proposed to overcome undesirable immunogenicity of VLPs consists of modifying them with immune masking agents, such as polyethylene glycol (PEG), which has been shown to suppress the primary antibody response (Jain and Jain, 2008). Another concern that must be kept in mind is that like any virus-based treatment, VLPs are not suitable for repetitive administration. The exception here is cancer immunotherapy, where the goal is to stimulate tumor recognition in an escalating manner. Initial enthusiasm for VLP-mediated gene therapy has been tempered by the lack of large-scale methods for adequate internalization and proper release of the desired nucleic acid, and further research will be necessary to overcome this problem (Pattenden et al., 2005). It is also worth noting, that the different mechanism of assembly of non-enveloped and enveloped VLPs impede in vitro encapsulation of foreign molecules in the latter.

\section{Concluding remarks}

Virus-like particles have been produced for a wide range of taxonomically and structurally distinct viruses and have unique advantages in terms of construction flexibility. Moreover, their versatility relies on their unique structural diversity and tailorable functionality. Potential uses of VLPs include vaccine production, vectors for gene therapy and targeted drug delivery, and molecular imaging tools (Fig. 3). However, translation from preclinical research to licensed products requires extensive studies in animal models that remain to be completed. Firstly, effective and scalable loading of cargo onto VLPs vectors requires further investigation. Futhermore, careful evaluation of the toxicity, biodistribution, stability in vivo, and clearance of VLPs will be crucial in order for these nanocarriers to be considered for medical use.

\section{Acknowledgments}

This work was supported by a Fuga grant from the National Science Center (AN; UMO-2013/08/S/NZ6/00730) and a LIDER grant from the National Centre for Research and Development (KP; Lider/27/55/L-2/10/2011). The Faculty of Biochemistry, Biophysics and Biotechnology at Jagiellonian University is a beneficiary of structural funds from the European Union (grant no: POIG.02.01.00-12-064/08 - "Molecular Biotechnology for Health"). The Facu lty of Biochemistry, Biophysics and Biotechnology is a partner of the Leading National Research Center (KNOW) supported by the Ministry of Science and Higher Education. 


\section{Literature}

Acosta-Rivero N., J.C. Aguilar, A. Musacchio,V. Falcón, A. Viña, M.C. de la Rosa and J. Morales. 2001. Characterization of the HCV core virus-like particles produced in the methylotrophic yeast Pichia pastoris. Biochem. Biophys. Res. Commun. 287: 122-125.

Aden D.P., A. Fogel, S. Plotkin, I.Damjanov and B.B. Knowles. 1979. Controlled synthesis of HBsAg in a differentiated human liver carcinoma-derived cell line. Nature 282: 615-616.

Agnandji S.T.L.B., J.F. Fernandes, B.P. Abossolo, B.G. Methogo, A.L. Kabwende, A.A. Adegnika, B. Mordmuller, S. Issifou, P.G. Kremsner, J. Sacarlal, P. Aide, M. Lanaspa, J.J. Aponte, S. Machevo, S. Acacio, H. Bulo, B. Sigauque, E. Macete, P. Alonso, S. Abdulla, N. Salim, R. Minja, M. Mpina, S. Ahmed, A.M. Ali, A.T. Mtoro, A.S. Hamad, P. Mutani, M. Tanner, H. Tinto, U. d'Alessandro, H. Sorgho and others. 2012. A phase 3 trial of RTS,S/AS01 malaria vaccine in African infants. N. Engl. J. Med. 367: 2284-2295.

Aires K.A., A.M. Cianciarullo, S.M. Carneiro, L.L. Villa, E. Boccardo, G. Pérez-Martinez, I. Perez-Arellano, M.L. Oliveira and P.L. Ho. 2006. Production of human papillomavirus type $16 \mathrm{~L} 1$ virus-like particles by recombinant Lactobacillus casei cells. Appl. Environ .Microbiol. 72: 745-752.

Akahata W., Z.Y. Yang, H. Andersen, S. Sun, H.A. Holdaway, W.P. Kong, M.G. Lewis, S. Higgs, M.G. Rossmann, S. Rao and others. 2010. A virus-like particle vaccine for epidemic Chikungunya virus protects nonhuman primates against infection. Nat. Med. 16: $334-338$.

Almeida J.D., D.C.Edwards, C.M. Brand and T.D. Heath. 1975. Formation of virosomes from influenza subunits and liposomes. Lancet 2: 899-901.

Bachmann M.F. and G.T. Jennings. 2011. Therapeutic vaccines for chronic diseases: successes and technical challenges. Philos. Trans. R. Soc. Lond. B Biol. Sci. 366: 2815-2822.

Barrett P.N., W. Mundt, O. Kistner and M.K. Howard. 2009. Vero cell platform in vaccine production: moving towards cell culturebased viral vaccines. Expert Rev. Vaccines 8: 607-618.

Baumert T.F., S. Ito, D.T. Wong and T.J. Liang. 1998. Hepatitis C virus structural proteins assemble into viruslike particles in insect cells. J.Virol. 72: 3827-3836.

Bergsdorf C., C. Beyer, V. Umansky, M. Werr and M. Sapp M. 2003. Highly efficient transport of carboxyfluorescein diacetate succinimidyl ester into COS7 cells using human papillomavirus-like particles. FEBS Lett. 536: 120-124.

Betenbaugh M., M. Yu, K. Kuehl, J. White, D. Pennock, K. Spik and C. Schmaljohn. 1995. Nucleocapsid- and virus-like particles assemble in cells infected with recombinant baculoviruses or vaccinia viruses expressing the $M$ and the $S$ segments of Hantaan virus. Virus Res. 38: 111-124.

Braun M., C. Jandus, P. Maurer, A. Hammann-Haenni, K. Schwarz, M.F Bachmann, D.E. Speiser and P. Romero. 2012. Virus-like particles induce robust human T-helper cell responses. Eur. J. Immunol. 42: 330-340.

Buonaguro L., M. Tagliamonte, M.L. Tornesello and F.M. Buonaguro. 2011. Developments in virus-like particle-based vaccines for infectious diseases and cancer. Expert Rev.Vaccines 10: 1569-1583. Chackerian B., D.R. Lowy and J.T. Schiller. 2001. Conjugation of a self-antigen to papillomavirus-like particles allows for efficient induction of protective autoantibodies. J. Clin. Invest. 108: 415-423. Chackerian B., M. Rangel, Z. Hunter and D.S. Peabody. 2006. Virus and virus-like particle-based immunogens for Alzheimer's disease induce antibody responses against amyloid-beta without concomitant T cell responses. Vaccine 24: 6321-6331.

Chandramouli S., A. Medina-Selby, D. Coit, M. Schaefer, T. Spencer, L.A. Brito, P. Zhang, G. Otten, C.W. Mandl, P.W. Mason and others. 2013. Generation of a parvovirus B19 vaccine candidate. Vaccine 31: 3872-3878.

Chang G.J., A.R. Hunt, D.A.Holmes, T. Springfield, T.S. Chiueh, J.T. Roehrig and D.J. Gubler. 2003. Enhancing biosynthesis and secretion of premembrane and envelope proteins by the chimeric plasmid of dengue virus type 2 and Japanese encephalitis virus. Virology 306: 170-180.

Charpilienne A., M. Nejmeddine, M. Berois, N. Parez, E. Neumann, E. Hewat, G. Trugnan and J. Cohen. 2001. Individual rotavirus-like particles containing 120 molecules of fluorescent protein are visible in living cells. J. Biol. Chem. 276: 29361-29367.

Chroboczek J., I. Szurgot and E. Szolajska. 2014. Virus-like particles as vaccine. Acta Biochim. Pol. 61: 531-539.

Deleré Y., O. Wichmann, S.J. Klug, M. van der Sande, M. Terhardt, F. Zepp and T. Harder. 2014. The efficacy and duration of vaccine protection against human papillomavirus: a systematic review and meta-analysis. Dtsch. Arztebl. Int. 111: 584-591.

Denis J., N. Majeau, E. Acosta-Ramirez, C. Savard, M.C. Bedard, S. Simard, K. Lecours, M. Bolduc, C. Pare, B. Willems and others 2007. Immunogenicity of papaya mosaic virus-like particles fused to a hepatitis $C$ virus epitope: evidence for the critical function of multimerization. Virology 363: 59-68.

El-Kamary S.S., M.F. Pasetti, P.M. Mendelman, S.F. Frey, D.I. Bernstein, J.J. Treanor, J. Ferreira, W.H. Chen, R. Sublett, C. Richardson and others. 2010. Adjuvanted intranasal Norwalk virus-like particle vaccine elicits antibodies and antibody-secreting cells that express homing receptors for mucosal and peripheral lymphoid tissues. J. Infect. Dis. 202: 1649-1658.

Fender P., G. Schoehn, J. Foucaud-Gamen, E. Gout, A. Garcel, E. Drouet and J. Chroboczek. 2003. Adenovirus dodecahedron allows large multimeric protein transduction in human cells. J. Virol. 77: 4960-4964.

Fuschiotti P., P. Fender, G. Schoehn and J.F. Conway. 2006. Development of the dodecahedral penton particle from adenovirus 3 for therapeutic application. J. Gen. Virol. 87: 2901-2905.

Garcel A., E. Gout, J. Timmins, J. Chroboczek and P. Fender 2006. Protein transduction into human cells by adenovirus dodecahedron using WW domains as universal adaptors. J. Gene. Med. 8: 524-531.

Gerber S., C. Lane, D.M. Brown, E. Lord, M. DiLorenzo, J.D. Clements, E. Rybicki, A.L. Williamson and R.C. Rose. 2001. Human papillomavirus virus-like particles are efficient oral immunogens when coadministered with Escherichia coli heat-labile enterotoxin mutant R192G or CpG DNA. J. Virol. 75: 4752-4760.

Gheysen D., E. Jacobs, F. de Foresta, C. Thiriart, M. Francotte, D. Thines and M. De Wilde. 1989. Assembly and release of HIV-1 precursor Pr55gag virus-like particles from recombinant baculovirus-infected insect cells. Cell 59: 103-112.

Gleiter S. and H. Lilie. 2003. Cell-type specific targeting and gene expression using a variant of polyoma VP1 virus-like particles. Biol. Chem. 384: 247-255.

Glenn G.M., G. Smith, L. Fries, R. Raghunandan, H. Lu, B. Zhou, D.N. Thomas, S.P. Hickman, E. Kpamegan, S. Boddapati and others. 2013. Safety and immunogenicity of a Sf9 insect cell-derived respiratory syncytial virus fusion protein nanoparticle vaccine. $\mathrm{Vac}$ cine 31: 524-532.

Goldmann C., N. Stolte, T. Nisslein, G. Hunsmann, W. Lüke and H. Petry. 2000. Packaging of small molecules into VP1-virus-like particles of the human polyomavirus JC virus. J. Virol. Methods 90 : 85-90.

Greco R., M. Michel, D. Guetard, M. Cervantes-Gonzalez, N. Pelucchi, S.Wain-Hobson, F. Sala and M. Sala. 2007. Production of recombinant HIV-1/HBV virus-like particles in Nicotiana tabacum and Arabidopsis thaliana plants for a bivalent plant-based vaccine. Vaccine 25: 8228-8240. 
Grgacic E.V. and D.A. Anderson. 2006. Virus-like particles: passport to immune recognition. Methods 40: 60-65.

Groothuis T.A. and J. Neefjes. 2005. The many roads to crosspresentation. J. Exp. Med. 202: 1313-1318.

Hanumantha Rao N., P. Baji Babu, L. Rajendra, R. Sriraman, Y.Y. Pang, J.T. Schiller and V.A. Srinivasan. 2011. Expression of codon optimized major capsid protein (L1) of human papillomavirus type 16 and 18 in Pichia pastoris; purification and characterization of the virus-like particles. Vaccine 29: 7326-7334.

Harper D.M., E.L. Franco, C. Wheeler, D.G. Ferris, D. Jenkins, A. Schuind, T. Zahaf, B. Innis, P. Naud, N.S. De Carvalho and others. 2004. Efficacy of a bivalent L1 virus-like particle vaccine in prevention of infection with human papillomavirus types 16 and 18 in young women: a randomised controlled trial. Lancet 364: 1757-1765.

Herbst-Kralovetz M., H.S. Mason and Q. Chen Q. 2010. Norwalk virus-like particles as vaccines. Expert Rev. Vaccines 9: 299-307.

Hjelm B.E., J. Kilbourne and M.M. Herbst-Kralovetz. 2014. TLR7 and 9 agonists are highly effective mucosal adjuvants for norovirus virus-like particle vaccines. Hum. Vaccin. Immunother. 10: $410-416$.

Jain A. and S.K. Jain. 2008. PEGylation: an approach for drug delivery. A review. Crit. Rev. Ther. Drug Carrier Syst. 25: 403-447.

Juarez V., H.A. Pasolli, A. Hellwig, N. Garbi and A.C. Arregui. 2012. Virus-like particles harboring CCL19, IL-2 and HPV16 E7 elicit protective $\mathrm{T}$ cell responses in HLA-A2 transgenic mice. Open Virol. J. 6: 270-276.

Kang S.M., Q. Yao, L. Guo and R.W. Compans. 2003. Mucosal immunization with virus-like particles of simian immunodeficiency virus conjugated with cholera toxin subunit B. J. Virol. 77: 9823-9830.

Kazaks A., R. Balmaks, T. Voronkova, V. Ose and P. Pumpens. 2008. Melanoma vaccine candidates from chimeric hepatitis B core virus-like particles carrying a tumor-associated MAGE-3 epitope. Biotechnol. J. 3: 1429-1436.

Keller S.A., K. Schwarz, V. Manolova, C.E. von Allmen, M.G. Kinzler, M. Bauer, S. Muntwiler, P. Saudan and M.F. Bachmann. 2010. Innate signaling regulates cross-priming at the level of DC licensing and not antigen presentation. Eur. J. Immunol. 40: 103-112.

Kimchi-Sarfaty C., M. Arora, Z. Sandalon, A. Oppenheim and M.M. Gottesman. 2003. High cloning capacity of in vitro packaged SV40 vectors with no SV40 virus sequences. Hum .Gene. Ther. 14: 167-177.

Kitai Y., H. Fukuda, T. Enomoto, Y. Asakawa, T. Suzuki, S. Inouye and H. Handa. 2011. Cell selective targeting of a simian virus 40 virus-like particle conjugated to epidermal growth factor. J. Biotechnol. 155: 251-256.

Kolesnikova L., B. Berghöfer, S. Bamberg and S. Becker. 2004. Multivesicular bodies as a platform for formation of the Marburg virus envelope. J. Virol. 78: 12277-12287.

Kushnir N., S.J. Streatfield and V. Yusibov. 2012. Virus-like particles as a highly efficient vaccine platform: diversity of targets and production systems and advances in clinical development. Vaccine 31: $58-83$.

Lee Y.T., K.H. Kim, E.J. Ko, Y.N. Lee, M.C. Kim, Y.M. Kwon, Y. Tang, M.K. Cho, Y.J. Lee and S.M. Kang. 2014. New vaccines against influenza virus. Clin. Exp. Vaccine Res. 3: 12-28.

Li T.C., J. Zhang, H. Shinzawa, M. Ishibashi, M. Sata, E.E. Mast, K. Kim, T. Miyamura and N. Takeda. 2000. Empty virus-like particle-based enzyme-linked immunosorbent assay for antibodies to hepatitis E virus. J. Med. Virol. 62: 327-333.

Liu F., S. Ge, L. Li, X.Wu, Z. Liu and Z. Wang. 2012. Virus-like particles: potential veterinary vaccine immunogens. Res. Vet. Sci. 93: 553-559.
Liu F., X. Wu, L. Li, Z. Liu and Z. Wang. 2013. Use of baculovirus expression system for generation of virus-like particles: successes and challenges. Protein Expr. Purif .90: 104-116.

Liu Y.V., M.J. Massare, D.L. Barnard, T. Kort, M. Nathan, L. Wang and G. Smith. 2011. Chimeric severe acute respiratory syndrome coronavirus (SARS-CoV) S glycoprotein and influenza matrix 1 efficiently form virus-like particles (VLPs) that protect mice against challenge with SARS-CoV. Vaccine 29: 6606-6613.

Ludwig C. and R. Wagner. 2007. Virus-like particles-universal molecular toolboxes. Curr. Opin. Biotechnol. 18: 537-545.

Lünsdorf H., C. Gurramkonda, A. Adnan, N. Khanna and U. Rinas. 2011. Virus-like particle production with yeast: ultrastructural and immunocytochemical insights into Pichia pastoris producing high levels of the hepatitis B surface antigen. Microb. Cell Fact 10: 48.

Malboeuf C.M., D.A. Simon, Y.E. Lee, H.A. Lankes, S. Dewhurst, J.G. Frelinger and R.C. Rose. 2007. Human papillomavirus-like particles mediate functional delivery of plasmid DNA to antigen presenting cells in vivo. Vaccine 25: 3270-3276.

Manolova V., A. Flace, M. Bauer, K. Schwarz, P. Saudan and M.F. Bachmann. 2008. Nanoparticles target distinct dendritic cell populations according to their size. Eur. J. Immunol. 38: 1404-1413. Mason H.S., D.M. Lam and C.J. Arntzen. 1992. Expression of hepatitis B surface antigen in transgenic plants. Proc. Natl. Acad. Sci. USA 89: 11745-11749.

Mateu M.G. 2011. Virus engineering: functionalization and stabilization. Protein Eng. Des. Sel. 24: 53-63.

Maurer P., G.T. Jennings, J. Willers, F. Rohner, Y. Lindman, K. Roubicek, W.A. Renner, P. Müller and M.F. Bachmann. 2005. A therapeutic vaccine for nicotine dependence: preclinical efficacy, and Phase I safety and immunogenicity. Eur. J. Immunol. 35: 2031-2040.

May T., S. Gleiter and H. Lilie. 2002. Assessment of cell type specific gene transfer of polyoma virus like particles presenting a tumor specific antibody Fv fragment. J. Virol. Methods 105: 147-157.

McGinnes L.W., H. Pantua, J.P. Laliberte, K.A. Gravel, S. Jain and T.G. Morrison. 2010. Assembly and biological and immunological properties of Newcastle disease virus-like particles. J. Virol. 84: 4513-4523.

Morein B., A. Helenius, K. Simons and V. Schirrmacher. 1979. Virus spike protein complexes and virosomes as effective subunit vaccines. Adv. Exp. Med. Biol. 114: 811-816.

Oh Y.K., T. Sohn, J.S. Park, M.J. Kang, H.G. Choi, J.A. Kim, W.K. Kim, J.J. Ko and C.K. Kim. 2004. Enhanced mucosal and systemic immunogenicity of human papillomavirus-like particles encapsidating interleukin-2 gene adjuvant. Virology 328: 266-273. Pan Y., T. Jia, Y. Zhang, K. Zhang, R. Zhang, J. Li and L. Wang. 2012. MS2 VLP-based delivery of microRNA-146a inhibits autoantibody production in lupus-prone mice. Int. J. Nanomedicine 7: 5957-5967.

Pattenden L.K., A.P. Middelberg, M. Niebert and D.I. Lipin. 2005. Towards the preparative and large-scale precision manufacture of virus-like particles. Trends Biotechnol. 23: 523-529.

Petry H., C. Goldmann, O. Ast and W. Lüke. 2003. The use of virus-like particles for gene transfer. Curr. Opin. Mol. Ther. 5: 524-528.

Petukhova N.V., T.V. Gasanova, P.A. Ivanov and J.G. Atabekov. 2014. High-level systemic expression of conserved influenza epitope in plants on the surface of rod-shaped chimeric particles. Viruses 6: 1789-1800.

Phelps J.P., N. Dang and L. Rasochova. 2007. Inactivation and purification of cowpea mosaic virus-like particles displaying peptide antigens from Bacillus anthracis. J.Virol. Methods 141: 146-153.

Pniewski T. 2012. Is an oral plant-based vaccine against hepatitis B virus possible? Curr. Pharm. Biotechnol .13: 2692-2704. 
Pushko P., P. Pumpens and E. Grens. 2013. Development of viruslike particle technology from small highly symmetric to large complex virus-like particle structures. Intervirology 56: 141-165.

Pushko P., T.M. Tumpey, F. Bu, J. Knell, R. Robinson and G. Smith. 2005. Influenza virus-like particles comprised of the HA, $\mathrm{NA}$, and M1 proteins of $\mathrm{H} 9 \mathrm{~N} 2$ influenza virus induce protective immune responses in BALB/c mice. Vaccine 23: 5751-5759.

Quan F.S., Y. Kim, S. Lee, H. Yi , S.M. Kang, J. Bozja, M.L. Moore and R.W. Compans. 2011. Viruslike particle vaccine induces protection against respiratory syncytial virus infection in mice. J. Infect. Dis. 204: 987-995.

Ramqvist T., K. Andreasson and T. Dalianis. 2007. Vaccination, immune and gene therapy based on virus-like particles against viral infections and cancer. Expert Opin. Biol. Ther. 7: 997-1007.

Reperant L.A., G.F. Rimmelzwaan and A.D. Osterhaus. 2014. Advances in influenza vaccination. F1000Prime Rep 6: 47.

Rodríguez-Limas W.A., K.E. Tyo, J. Nielsen, O.T. Ramírez and L.A. Palomares. 2011. Molecular and process design for rotaviruslike particle production in Saccharomyces cerevisiae. Microb. Cell Fact. 10: 33.

Roldão A.,M.C. Mellado, L.R. Castilho, M.J. Carrondo and P.M. Alves. 2010. Virus-like particles in vaccine development. Expert Rev. Vaccines 9: 1149-1176.

Rosales-Mendoza S., N. Rubio-Infante, D.O. Govea-Alonso and L. Moreno-Fierros. 2012. Current status and perspectives of plantbased candidate vaccines against the human immunodeficiency virus (HIV). Plant Cell Rep. 31: 495-511.

Roy P. and R. Noad. 2008. Virus-like particles as a vaccine delivery system: myths and facts. Hum. Vaccin 4: 5-12.

Rychlowska M., B. Gromadzka, K. Bieńkowska-Szewczyk and B. Szewczyk . 2011. Application of baculovirus-insect cell expression system for human therapy. Curr. Pharm. Biotechnol. 12: 1840-1849. Sakuragi S., T. Goto, K. Sano and Y. Morikawa . 2002. HIV type 1 Gag virus-like particle budding from spheroplasts of Saccharomyces cerevisiae. Proc. Natl. Acad. Sci. USA 99: 7956-7961.

Sällberg M.,J. Hughes, J. Jones, T.R. Phillips and D.R. Milich. 2002. A malaria vaccine candidate based on a hepatitis $B$ virus core platform. Intervirology 45: 350-361.

Sánchez-Rodríguez S.P., L. Münch-Anguiano, O. Echeverría, G. Vázquez-Nin, M. Mora-Pale, J.S. Dordick and I. Bustos-Jaimes. 2012. Human parvovirus B19 virus-like particles: In vitro assembly and stability. Biochimie 94: 870-878.

Scotti N. and E.P. Rybicki. 2013. Virus-like particles produced in plants as potential vaccines. Expert Rev. Vaccines 12: 211-224.

Senti G., P. Johansen, S. Haug, C. Bull, C. Gottschaller, P. Müller, T. Pfister, P. Maurer, M.F. Bachmann, N. Graf and others. 2009. Use of A-type CpG oligodeoxynucleotides as an adjuvant in allergen-specific immunotherapy in humans: a phase I/Ila clinical trial. Clin. Exp. Allergy 39: 562-570.

Seo H.S., J.S. Park, K.Y. Han, K.D. Bae, S.J. Ahn, H.A. Kang and J. Lee. 2008. Analysis and characterization of hepatitis B vaccine particles synthesized from Hansenula polymorpha. Vaccine 26: 4138-4144. Seow Y. and M.J. Wood. 2009. Biological gene delivery vehicles: beyond viral vectors. Mol. Ther. 17: 767-777.

Shen L., J. Zhou, Y. Wang, N. Kang, X. Ke, S. Bi and L. Ren. 2014. Efficient encapsulation of Fe3 O4 nanoparticles into genetically engineered hepatitis B core virus-like particles through a specific interaction for potential bioapplications. Small ?????

Soulié J.C., P. Devillier, J. Santarelli, A. Goudeau, P. Vermeulen, M. Guellier, P. Saliou, A. M. Hillion, F. Tron and J. Huchet. 1991.
Immunogenicity and safety in newborns of a new recombinant hepatitis $\mathrm{B}$ vaccine containing the $\mathrm{S}$ and pre-S2 antigens. Vaccine 9: 545-548.

Takehara K., D. Ireland and D.H. Bishop. 1988. Co-expression of the hepatitis B surface and core antigens using baculovirus multiple expression vectors. J. Gen. Virol. 69 ( Pt 11): 2763-2777.

Tang Y.X., L.F. Jiang, J.M. Zhou, Y. Yin, X.M. Yang, W.Q. Liu and D.Y. Fang. 2012. Induction of virus-neutralizing antibodies and $\mathrm{T}$ cell responses by dengue virus type 1 virus-like particles prepared from Pichia pastoris. Chin. Med. J. (Engl) 125: 1986-1992.

Tissot A.C., P. Maurer, J. Nussberger, R. Sabat, T. Pfister, S. Ignatenko, H.D. Volk, H. Stocker, P. Müller, G.T. Jennings and others. 2008. Effect of immunisation against angiotensin II with CYT006-AngQb on ambulatory blood pressure: a doubleblind, randomised, placebo-controlled phase IIa study. Lancet 371: 821-827.

Tissot A.C., R. Renhofa, N. Schmitz, I. Cielens, E. Meijerink, V. Ose, G.T. Jennings, P. Saudan, P. Pumpens and M.F. Bachmann. 2010. Versatile virus-like particle carrier for epitope based vaccines. PLoS One 5: e9809.

Tomé-Amat J.,L. Fleischer, S.A. Parker, C. Bardliving and C. Batt. 2014. Secreted production of assembled Norovirus virus-like particles from Pichia pastoris. Microb. Cell Fact. 13: 134.

Valenzuela P., A. Medina, W.J. Rutter, G. Ammerer and B.D. Hall. 1982. Synthesis and assembly of hepatitis B virus surface antigen particles in yeast. Nature 298: 347-350.

Wojta-Stremayr D. and W.F. Pickl. 2013. Fluorosomes: fluorescent virus-like nanoparticles that represent a convenient tool to visualize receptor-ligand interactions. Sensors (Basel) 13: 8722-8749.

Woo M.K., J.M. An, J.D. Kim, S.N. Park and H.J. Kim. 2008. Expression and purification of human papillomavirus 18 L1 viruslike particle from saccharomyces cerevisiae. Arch.Pharm. Res. 31: 205-209.

Wu L., L. Jiang, Z. Zhou, J. Fan, Q. Zhang, H. Zhu, Q. Han and Z. Xu. 2003. Expression of foot-and-mouth disease virus epitopes in tobacco by a tobacco mosaic virus-based vector. Vaccine 21: 4390-4398.

Yamayoshi S. and Y. Kawaoka. 2007. Mapping of a region of Ebola virus VP40 that is important in the production of virus-like particles. J. Infect. Dis. 196 Suppl 2: S291-295.

Yusibov V., D.C. Hooper, S.V. Spitsin, N. Fleysh, R.B. Kean, T. Mikheeva, D. Deka, A. Karasev, S. Cox, J. Randall and others. 2002. Expression in plants and immunogenicity of plant virus-based experimental rabies vaccine. Vaccine 20: 3155-3164.

Zeltins A. 2013. Construction and characterization of virus-like particles: a review. Mol. Biotechnol. 53: 92-107.

Zeng C.Q., M. Labbé, J. Cohen, B.V. Prasad, D. Chen, R.F. Ramig and M.K. Estes. 1994. Characterization of rotavirus VP2 particles. Virology 201: 55-65.

Zhao Q., W. Chen, Y. Chen, L. Zhang, J. Zhang and Z. Zhang. 2011. Self-assembled virus-like particles from rotavirus structural protein VP6 for targeted drug delivery. Bioconjug. Chem. 22: 346-352.

Zochowska M., A. Paca, G Schoehn, J.P. Andrieu, J. Chroboczek, B. Dublet. and E. Szolajska. 2009. Adenovirus dodecahedron, as a drug delivery vector. PLoS One 4: e5569.

Zuckerman A.J. 1980. Prophylaxis of hepatitis type B: immunoglobulins and vaccines. Clin Gastroenterol 9: 65-83.

Zuckerman A.J. 1985. Subunit, recombinant and synthetic hepatitis B vaccines. Microbiol. Sci. 2: 129-130, 133-128. 
